Supporting Information for

\title{
Substantial near-field air quality improvements at a general aviation airport following a runway shortening
}

Neelakshi Hudda ${ }^{1 *}$ (ORCID: 0000-0002-2886-5458), Scott Fruin ${ }^{2}$ (ORCID: 00000002-2953-0457), John L Durant ${ }^{1}$ (ORCID: 0000-0002-7016-1622)

${ }^{1}$ Department of Civil and Environmental Engineering, Tufts University, 200 College Avenue, Medford, MA 02155, USA

${ }^{2}$ Department of Preventive Medicine, Keck School of Medicine, University of Southern California, 2001 N. Soto Street, Los Angeles, CA 90033 USA

Number of pages: 16

Number of figures: 13

Number of tables: 5 


\section{S1. Methods}

Table S1: Instruments used to conduct air quality monitoring

\begin{tabular}{|l|l|l|}
\hline Pollutant & Runway Site & Residential Site \\
\hline BC & $\begin{array}{l}\text { Magee Scientific Aethalometer AE33, } \\
\text { 1-minute resolution }\end{array}$ & $\begin{array}{l}\text { Magee Scientific Aethalometer AE-16, } \\
\text { 5-minute resolution }\end{array}$ \\
\hline PNC & $\begin{array}{l}\text { TSI Incorporated Environmental } \\
\text { Particle Counter (CPC 3783), 1-second } \\
\text { resolution }\end{array}$ & $\begin{array}{l}\text { TSI Incorporated Environmental Particle } \\
\text { Counter (CPC 3783), 1-second } \\
\text { resolution }\end{array}$ \\
\hline PM $_{2.5}$ & $\begin{array}{l}\text { Harvard Personal Exposure Monitor } \\
\text { (H-PEM), 7- to 15-day intervals }\end{array}$ & $\begin{array}{l}\text { Harvard Personal Exposure Monitor (H- } \\
\text { PEM), 7- to 15-day intervals }\end{array}$ \\
\hline
\end{tabular}

\section{Data Quality Assurance Procedures}

Both CPCs were calibrated by the manufacturer immediately before the first monitoring period. To ensure the results were comparable between the two instruments, the CPCs were run side-by-side before and after the fourth monitoring period to check agreement. Agreement was always within the manufacturerspecified agreement of $\pm 20 \%$. See Figures S1-S2 in the for the 24 -hours side-by-side test results. The sideby-side comparison at the start of the campaign was conducted at the runway site and the side-by-side at the end of the campaign was conducted in the laboratory.

As part of our analyses, readings from the lowest reading CPC were adjusted to match the higher reading CPC by statistical matching (least squares linear regression). The first two weeks of the data used an adjustment factor of $\sim 15 \%$ based on the side-by-side at the beginning of the monitoring period 4 , and last two weeks of data was adjusted by the factor of $\sim 18 \%$ based on the side-by-side comparison at the end of monitoring period 4.

For BC, a single-wavelength $(880 \mathrm{~nm})$ Model AE16 was used at the residential site. Before deployment ambient side-by-side tests between AE33 and AE16 were conducted and for the $880 \mathrm{~nm}$ wavelength channel the agreement was within $10 \%\left(r^{2}=0.9\right)$. AE16 measurements were adjusted to be in agreement with AE33 based on the least-squares, linear regression fit of data from the side-by-side test shown in Figure S3. 


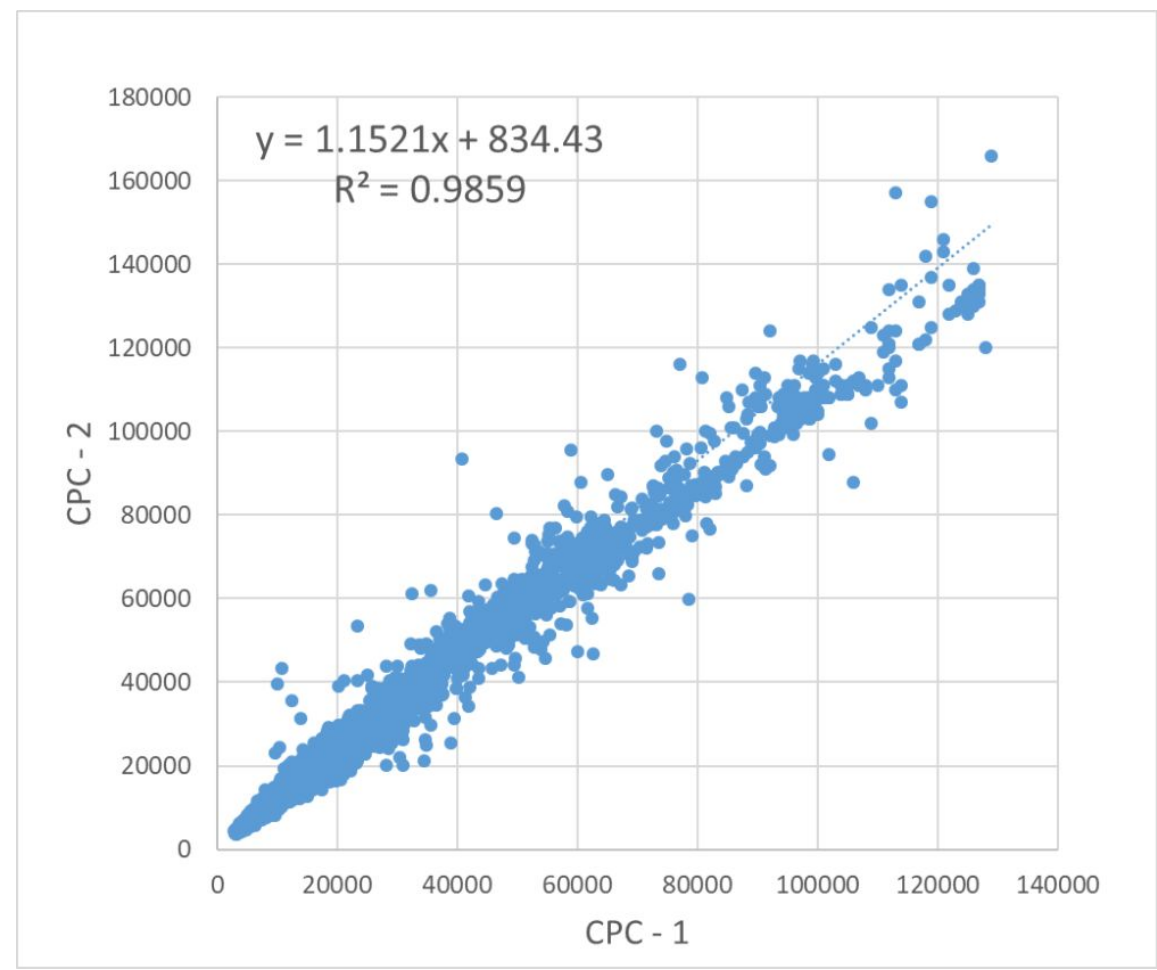

Figure S1: Side-by-side comparison of the two CPCs used in this study before the beginning of monitoring period 4.

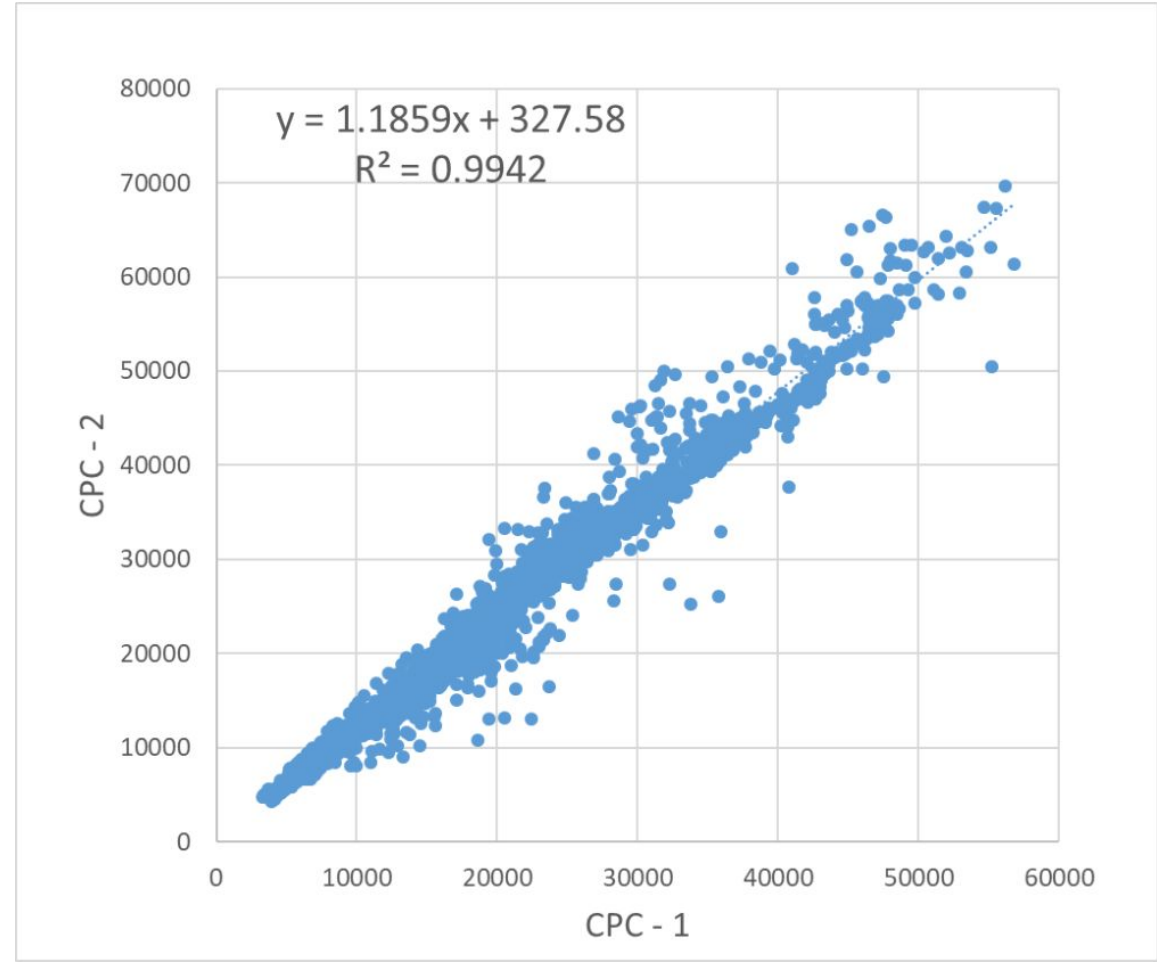

Figure S2: Side-by-side comparison of the two CPCs used in this study at the end of monitoring period 4. 


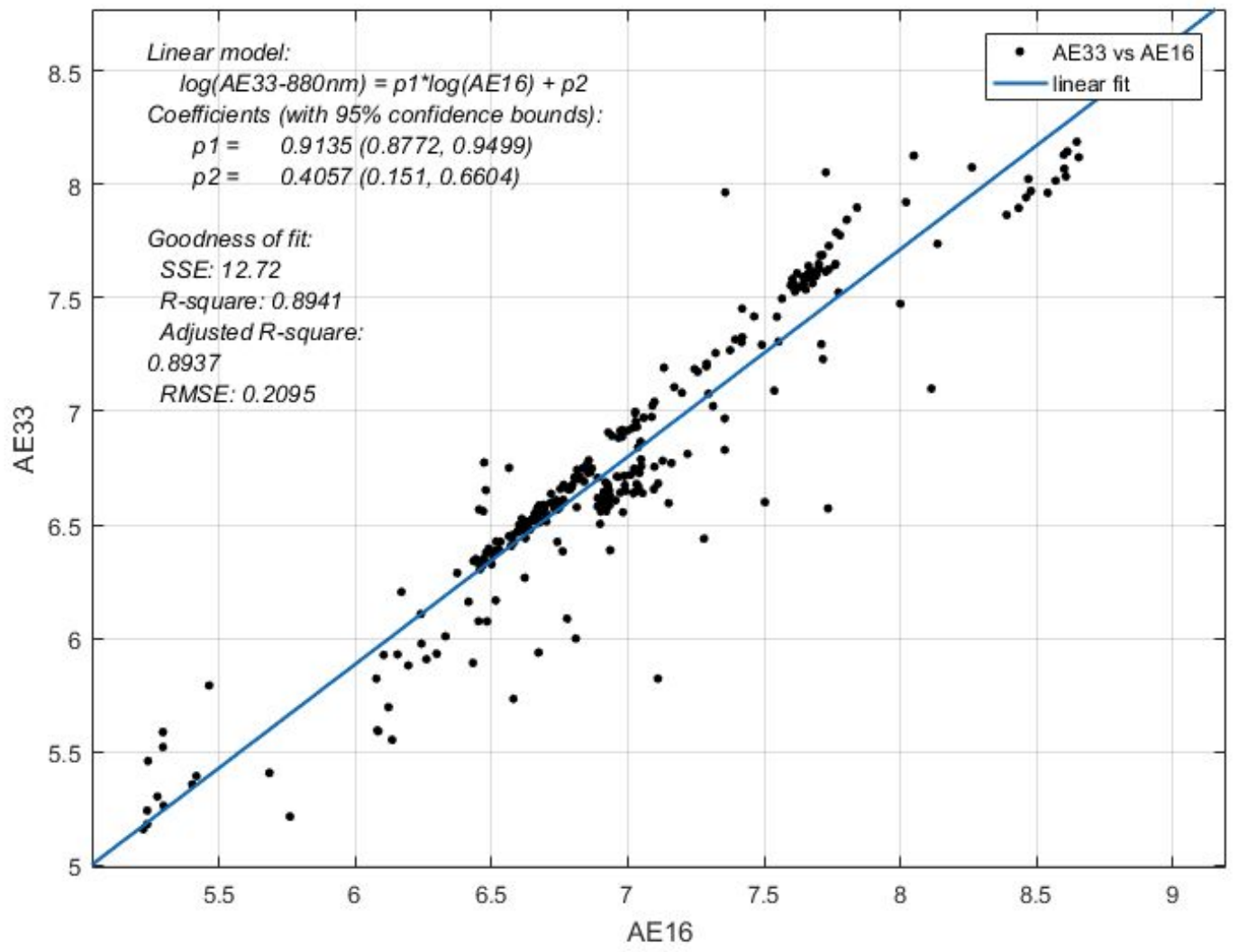

Figure S3: Side-by-side comparison of the two Aethalometers used in this study. 




Figure S4: Annual wind rose (December 2017-November 2018) based on measurements conducted by NWS at Santa Monica Airport. Each spoke indicates the direction from which the wind is blowing from. 



Figure S5: Wind roses for the phases of the study. (a): pre-runway-shortening, (b) airport shutdown during runway shortening, and (c) post-runway-shortening and $d$ : one-year later period of the monitoring. Each spoke indicates the direction from which the wind is blowing from. 
Table S2: Total operations at SMO from TFMSC for various weight classes for the last two decades.

\begin{tabular}{|c|c|c|c|c|c|c|c|c|}
\hline Year & $\begin{array}{l}\text { Heavy } \\
\text { Eqpt }\end{array}$ & $\begin{array}{l}\text { Large } \\
\text { Commuter } \\
\text { Eqpt }\end{array}$ & $\begin{array}{l}\text { Large } \\
\text { Jet } \\
\text { Eqpt }\end{array}$ & $\begin{array}{l}\text { Medium } \\
\text { Commuter } \\
\text { Eqpt }\end{array}$ & $\begin{array}{l}\text { Small } \\
\text { Eqpt }\end{array}$ & Other & $\begin{array}{l}\text { Unknown } \\
\text { or No Data }\end{array}$ & Total \\
\hline 2001 & 7 & 213 & 3 & 13479 & 16862 & 77 & 358 & 30999 \\
\hline 2002 & 4 & 162 & 3 & 16121 & 16674 & 32 & 281 & 33277 \\
\hline 2003 & 2 & 233 & 2 & 16035 & 15751 & 27 & 270 & 32320 \\
\hline 2004 & 11 & 339 & 2 & 17632 & 18053 & 21 & 210 & 36268 \\
\hline 2005 & 16 & 355 & 2 & 17614 & 17467 & 31 & 175 & 35660 \\
\hline 2006 & 4 & 471 & & 18331 & 16686 & 35 & 115 & 35642 \\
\hline 2007 & 5 & 408 & 3 & 19252 & 16361 & 40 & 97 & 36166 \\
\hline 2008 & 7 & 277 & 2 & 15220 & 19583 & 139 & 138 & 35366 \\
\hline 2009 & 9 & 241 & 2 & 12560 & 17581 & 113 & 120 & 30626 \\
\hline 2010 & 3 & 214 & 1 & 11753 & 16554 & 55 & 97 & 28677 \\
\hline 2011 & 2 & 189 & 1 & 12041 & 13441 & 42 & 78 & 25794 \\
\hline 2012 & 1 & 179 & & 11569 & 13590 & 40 & 65 & 25444 \\
\hline 2013 & & 219 & & 12291 & 15033 & 46 & 63 & 27652 \\
\hline 2014 & & 189 & & 11851 & 15745 & 65 & 67 & 27917 \\
\hline 2015 & 2 & 187 & & 12265 & 18964 & 54 & 56 & 31528 \\
\hline 2016 & 1 & 146 & 3 & 13208 & 13656 & 38 & 45 & 27097 \\
\hline 2017 & & 95 & 2 & 11892 & 11935 & 40 & 52 & 24016 \\
\hline 2018 & 1 & 8 & & 1068 & 10729 & 46 & 55 & 11907 \\
\hline 2019 & 2 & 12 & 2 & 1019 & 10581 & 52 & 28 & 11696 \\
\hline 2020 & & 13 & & 572 & 7204 & 89 & 23 & 7901 \\
\hline
\end{tabular}


Table S3: Total operations at SMO from TFMSC for various engine types by weight classes for the year preceding the shortening (2016), the year of the shortening (2017) and two years post shortening (2018-2019).

\begin{tabular}{|c|c|c|c|c|c|c|c|}
\hline $\begin{array}{l}\text { Engine } \\
\text { Type }\end{array}$ & $\begin{array}{l}\text { Heavy } \\
\text { Eqpt }\end{array}$ & $\begin{array}{l}\text { Large } \\
\text { Commuter } \\
\text { Eqpt }\end{array}$ & $\begin{array}{l}\text { Large Jet } \\
\text { Eqpt }\end{array}$ & $\begin{array}{l}\text { Medium } \\
\text { Commuter } \\
\text { Eqpt }\end{array}$ & $\begin{array}{l}\text { Small } \\
\text { Eqpt }\end{array}$ & $\begin{array}{l}\text { Other, No } \\
\text { Data or } \\
\text { Unknown }\end{array}$ & Total \\
\hline \multicolumn{8}{|c|}{2016} \\
\hline Jet & 1 & 125 & 1 & 12629 & 3884 & 5 & 16645 \\
\hline Piston & & 2 & & 7 & 5562 & 7 & 5578 \\
\hline Turbine & & 19 & & 360 & 3824 & 19 & 4222 \\
\hline Unknown & & & 2 & 212 & 386 & 52 & 652 \\
\hline \multicolumn{8}{|c|}{2017} \\
\hline Jet & & 70 & 2 & 11567 & 3606 & 11 & 15256 \\
\hline Piston & & 2 & & 5 & 4513 & 18 & 4538 \\
\hline Turbine & & 23 & & 319 & 3608 & 17 & 3967 \\
\hline Unknown & & & & 1 & 208 & 46 & 255 \\
\hline \multicolumn{8}{|c|}{2018} \\
\hline Jet & 1 & & & 749 & 2130 & 2 & 2882 \\
\hline Piston & & 2 & & 4 & 4786 & 16 & 4808 \\
\hline Turbine & & 6 & & 315 & 3673 & 24 & 4018 \\
\hline Unknown & & & & & 140 & 59 & 199 \\
\hline \multicolumn{8}{|c|}{2019} \\
\hline Jet & & & 2 & 758 & 2259 & 0 & 3019 \\
\hline Piston & 2 & & & 1 & 4764 & 14 & 4781 \\
\hline Turbine & & 12 & & 259 & 3338 & 13 & 3622 \\
\hline Unknown & & & & 1 & 220 & 53 & 274 \\
\hline
\end{tabular}


Table S4: Fraction of flight activity of runway 21 based on the flights for which runway assignment was available in the data provided by airport management.

\begin{tabular}{|c|c|c|c|c|c|c|}
\hline & \multicolumn{2}{|l|}{ Jets } & \multicolumn{2}{|c|}{ Turboprop } & \multicolumn{2}{|c|}{ Propeller } \\
\hline Monitoring Dates & Arrivals & Departures & Arrivals & Departures & Arrivals & Departures \\
\hline \multicolumn{7}{|l|}{ Pre-shortening } \\
\hline $2017 / 12 / 04-2017 / 12 / 12$ & $75 \%$ & $94 \%$ & $70 \%$ & $82 \%$ & $86 \%$ & $89 \%$ \\
\hline \multicolumn{7}{|l|}{ Shutdown } \\
\hline $2017 / 12 / 13-2017 / 12 / 22$ & \multicolumn{6}{|c|}{$\mathrm{n} / \mathrm{a}$} \\
\hline \multicolumn{7}{|l|}{ Post-shortening } \\
\hline $2018 / 12 / 23-2018 / 01 / 15$ & $92 \%$ & $80 \%$ & $98 \%$ & $100 \%$ & $99 \%$ & $97 \%$ \\
\hline \multicolumn{7}{|l|}{ Year-later } \\
\hline $2018 / 11 / 23-2018 / 12 / 23$ & $93 \%$ & $97 \%$ & $92 \%$ & $94 \%$ & $92 \%$ & $93 \%$ \\
\hline
\end{tabular}




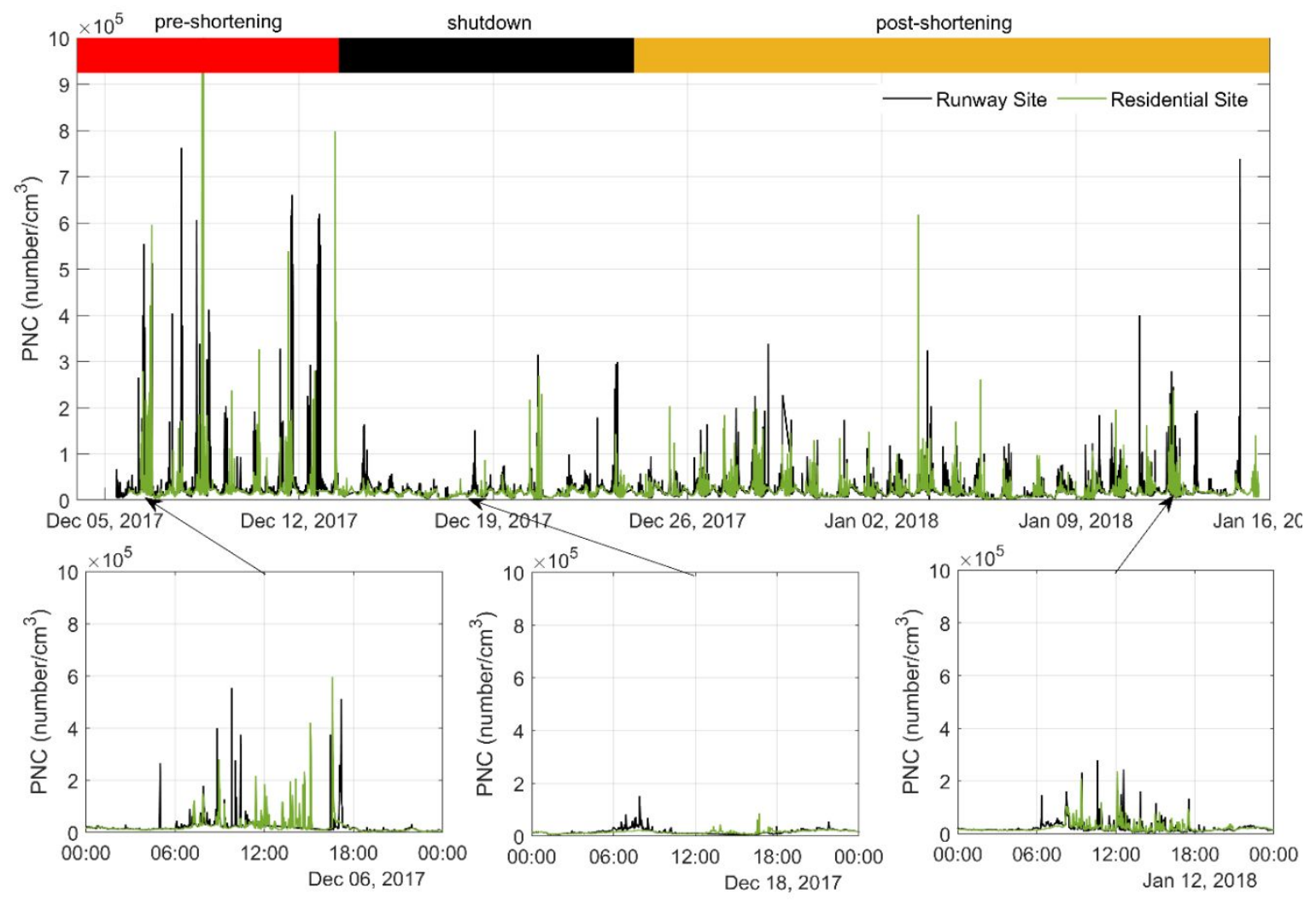

Figure S6: Time-series for particle number concentration (PNC) measured at the runway and residential site during pre-shortening, during shutdown and post-shortening.

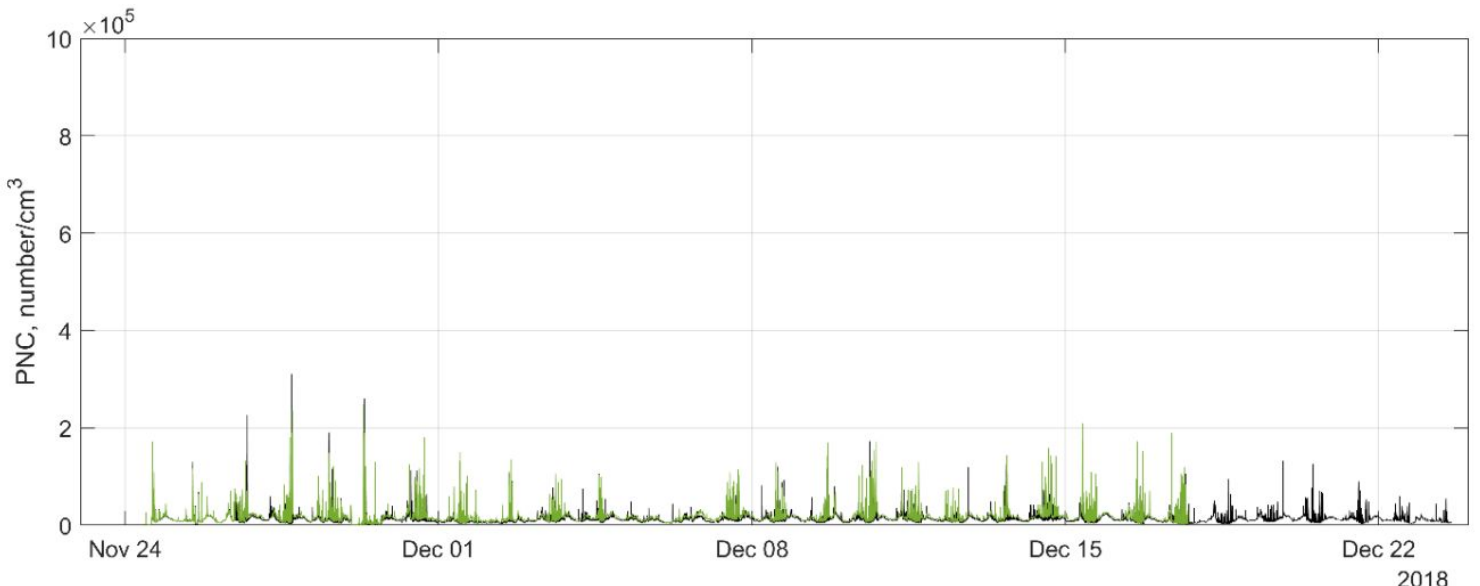

Figure S7: Time-series for particle number concentration (PNC) measured at the runway and residential site during year after shortening. 




Figure S8: Time-series for $B C$ concentration measured at the runway and residential site during preshortening, during shutdown and post-shortening. Note the ten-fold difference in y-axis scale between the phase-wide times series versus the individual days.

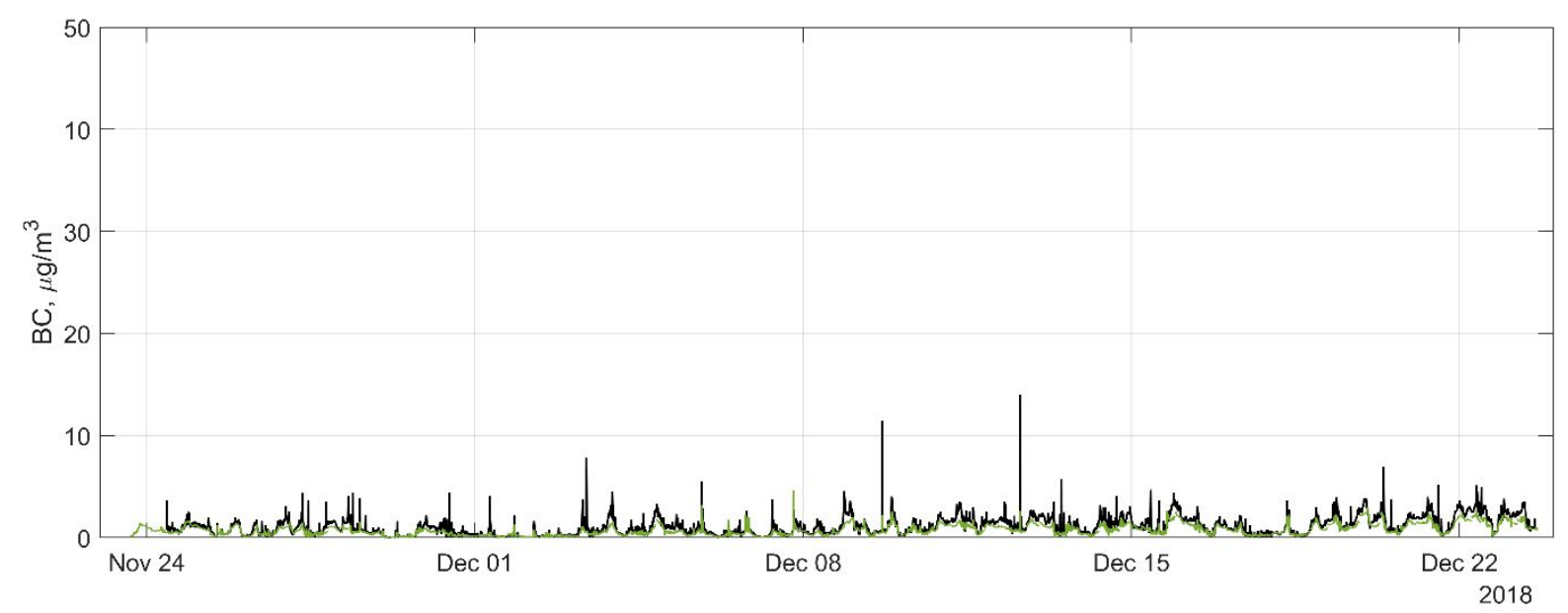

Figure S9: Time-series for BC concentration measured at the runway and residential site during year after shortening. 

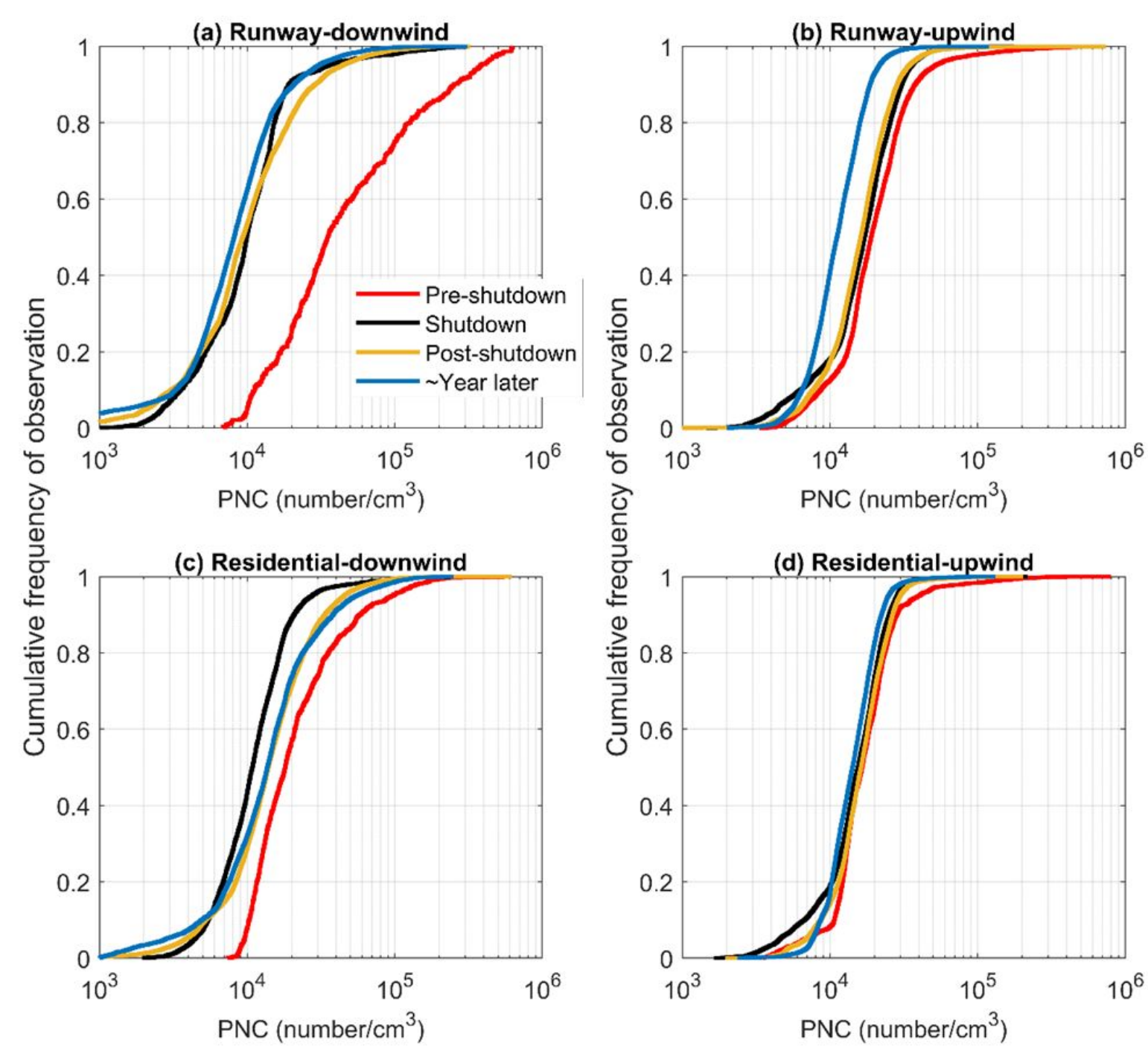

(b) Runway-upwind

(d) Residential-upwind

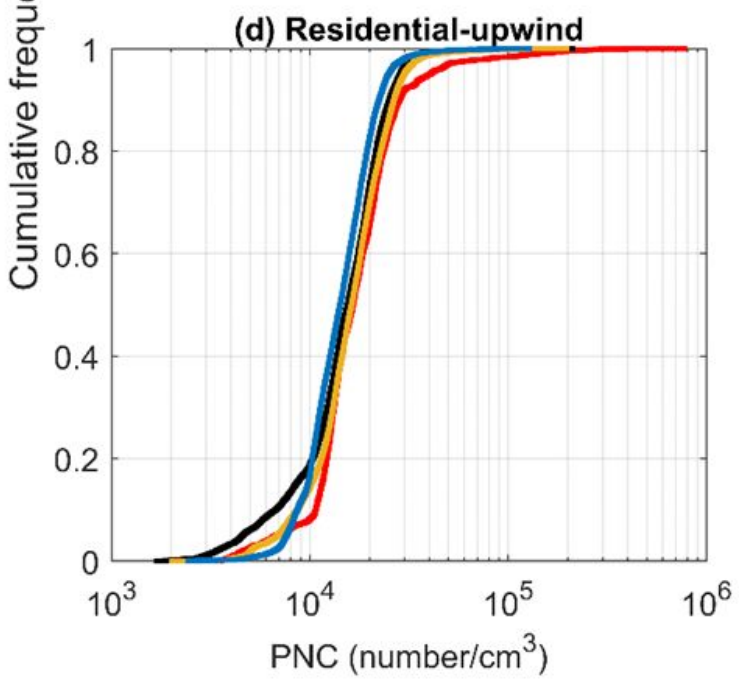

Figure S10: Cumulative frequency of observation for particle number concentration (PNC) (averaged to 1-min) during the different phases of the air quality monitoring study, separated by uwind conditions that orient the sites downwind or upwind of the airport.

The PNC distributions of one-minute averages shown in Figure S10 were tested for statistically-significant differences in central tendency (median of the averages). Compared to the distributions when the runway site was downwind of the airport during the pre-shortening sub-phase, the median of the averages was statistically significantly lower during shutdown ( $p$-value $<0.001)$, year later ( $p$-value $<0.001$ ) and postshortening ( $p$-value $<0.001$ ). The year later median was also statistically-significantly lower than that during shutdown period ( $p$-value $<0.001$ ).

Similar to the runway site, when the residential site was downwind of the airport, statistically significantly lower median concentrations than pre-shortening were observed during shutdown ( $p$-value $<0.001$ ), and $\sim$ year later ( $p$-value $<0.001$ ) and post-shortening ( $p$-value $<0.001)$. The $\sim$ year later median was higher than that during shutdown period. ( $p$-value $<0.001$ ). 

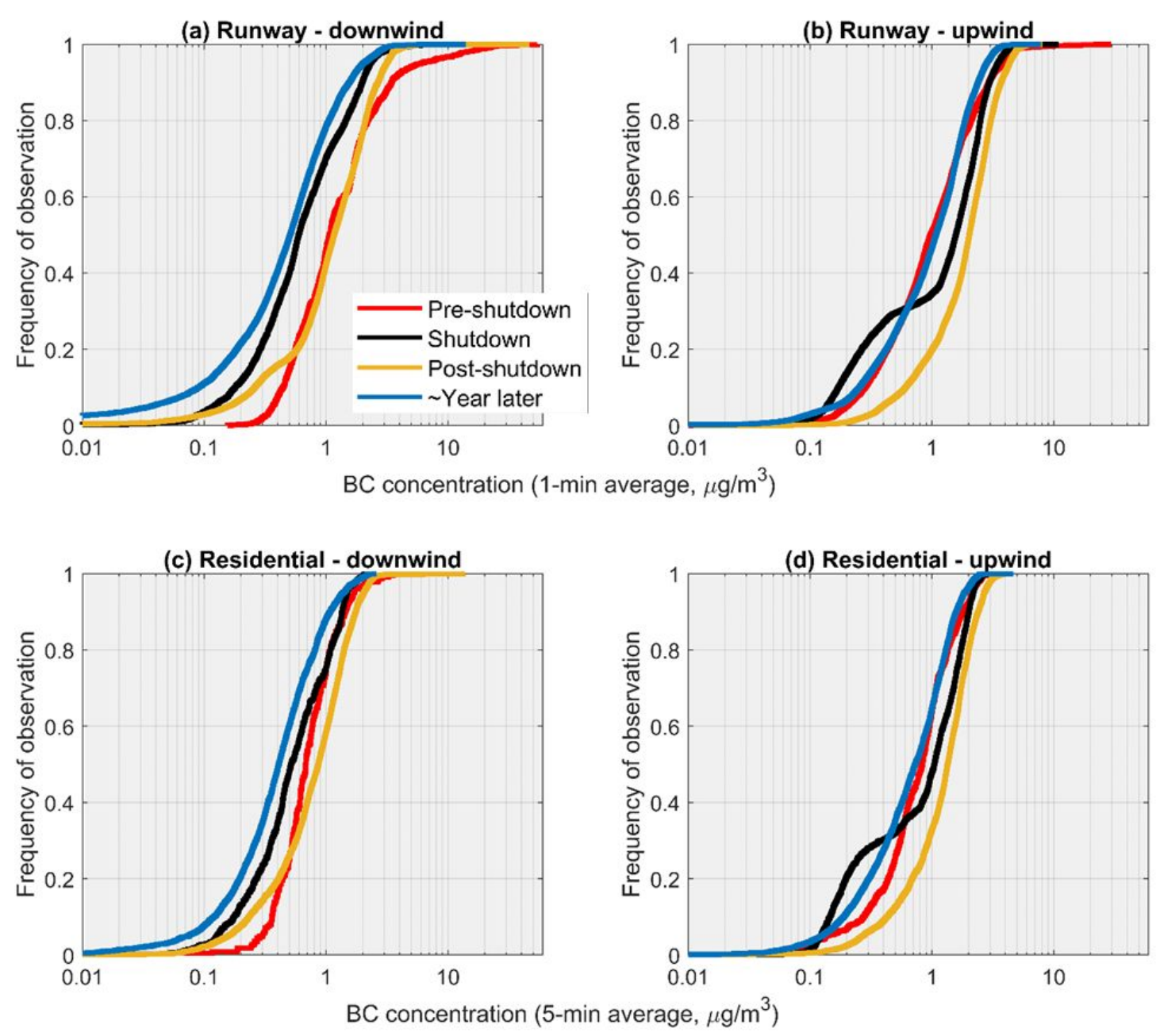

Figure S11: Cumulative frequency of observation for BC concentrations (measured at 1-min and 5-min resolution) during the different phases of the air quality monitoring study separated by wind conditions that orient the sites downwind or upwind of the airport.

The BC concentration distributions shown in Figure S11 were also tested for statistically-significant differences in central tendency (median) of the one- and five-minute resolution averages. Compared to the median when the runway site was downwind of the airport during the pre-shortening sub-phase, significantly lower median average concentrations were observed during shutdown ( $p$-value $<0.001$ ) and $\sim$ year later ( $p$-value $<0.001$ ), but not post-shortening ( $p$-value $=0.18$ ). Further, the $\sim$ year later median was also significantly lower than that during the shutdown period ( $p$-value $<0.001$ ). Similarly, when the residential site was downwind of the airport, significantly lower median concentrations were observed during shutdown ( $p$-value $<0.001$ ) and $\sim$ year later ( $p$-value $<0.001$ ) compared to pre-shortening, but not post-shortening ( $p$-value $=0.995)$, and the $\sim$ year later median was also lower than that during the shutdown period ( $p$-value $<0.001)$. 

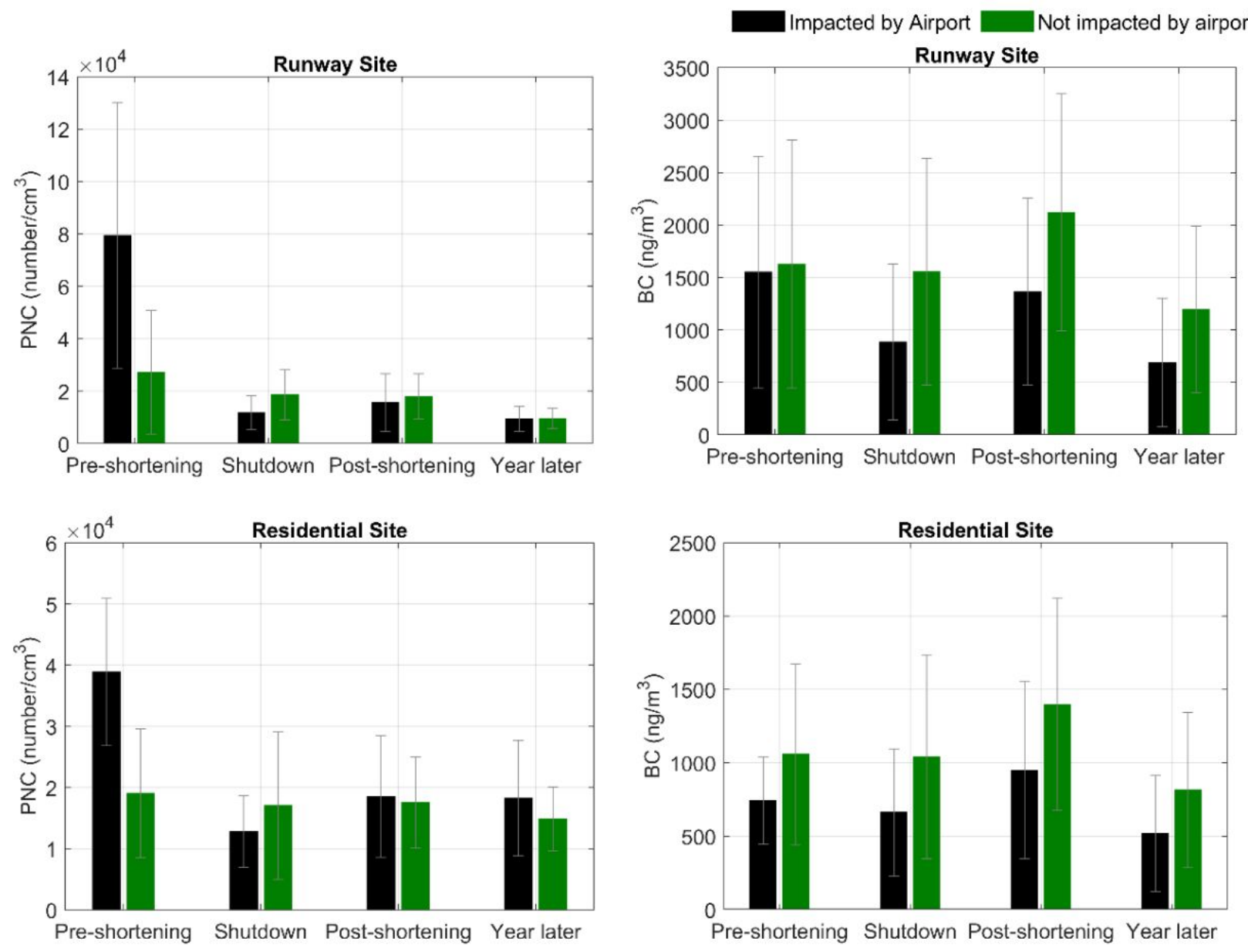

Figure S12: Comparison of concentrations when monitoring sites were downwind and not downwind of the airport. 


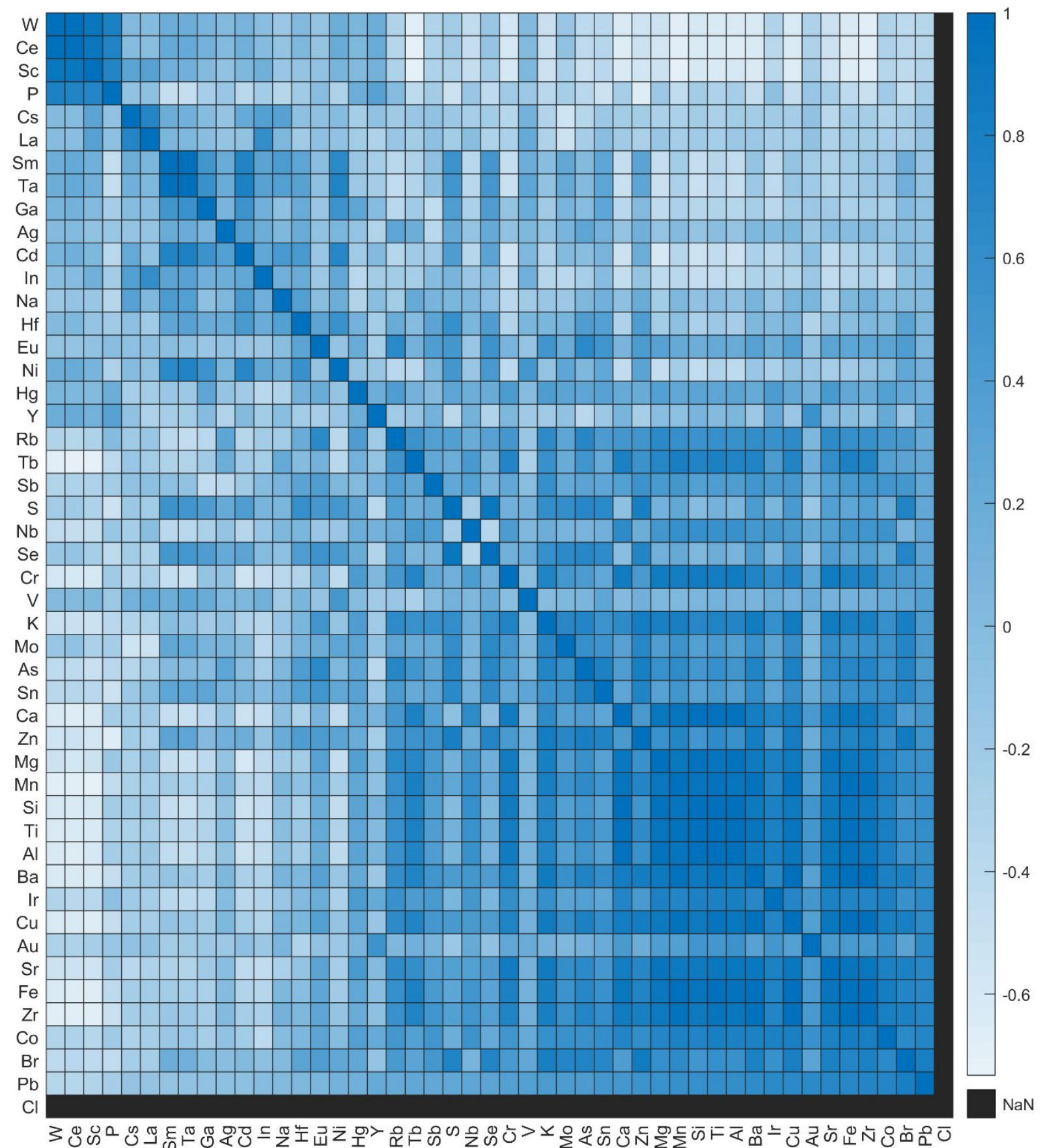

Figure S13: Correlation heat map between elements and all samples at both sites. 
Table S5: Monitoring schedule for time-integrated PM2.5 monitoring

\begin{tabular}{|c|c|c|c|c|}
\hline Site & & Phase & Start Date & End Date \\
\hline Residential & & Pre-shutdown & \multicolumn{2}{|c|}{ QAQC fail } \\
\hline Runway & & Pre-shutdown & $12 / 4 / 2017$ & $12 / 13 / 2017$ \\
\hline Residential & \multirow[t]{2}{*}{ Duplicates } & Shutdown & $12 / 12 / 2017$ & $12 / 23 / 2017$ \\
\hline Residential & & Shutdown & $12 / 12 / 2017$ & $12 / 23 / 2017$ \\
\hline Runway & \multirow[t]{2}{*}{ Duplicates } & Shutdown & $12 / 13 / 2017$ & $12 / 23 / 2017$ \\
\hline Runway & & Shutdown & $12 / 13 / 2017$ & $12 / 23 / 2017$ \\
\hline Residential & & Post-Shutdown* & $12 / 23 / 2017$ & $1 / 3 / 2018$ \\
\hline Residential & & Post-Shutdown* & $1 / 3 / 2018$ & $1 / 15 / 2018$ \\
\hline Residential & & Post-Shutdown** & $12 / 23 / 2017$ & $1 / 15 / 2018$ \\
\hline Runway & & Post-Shutdown* & $12 / 23 / 2017$ & $1 / 3 / 2018$ \\
\hline Runway & & Post-Shutdown* & $1 / 3 / 2018$ & $1 / 15 / 2018$ \\
\hline Runway & & Post-Shutdown** & $12 / 23 / 2017$ & $1 / 15 / 2018$ \\
\hline Runway & \multirow[t]{2}{*}{ Duplicates } & Year-later & $12 / 8 / 2018$ & $12 / 23 / 2018$ \\
\hline Runway & & Year-later & $12 / 8 / 2018$ & $12 / 23 / 2018$ \\
\hline Runway & \multirow[t]{2}{*}{ Duplicates } & Year-later & $11 / 24 / 2018$ & $12 / 8 / 2018$ \\
\hline Runway & & Year-later & $11 / 24 / 2018$ & $12 / 8 / 2018$ \\
\hline Residential & \multirow[t]{2}{*}{ Duplicates } & Year-later & $12 / 8 / 2018$ & $12 / 23 / 2018$ \\
\hline Residential & & Year-later & $12 / 8 / 2018$ & $12 / 23 / 2018$ \\
\hline Residential & \multirow[t]{2}{*}{ Duplicates } & Year-later & $11 / 24 / 2018$ & $12 / 8 / 2018$ \\
\hline Residential & & Year-later & $11 / 24 / 2018$ & $12 / 8 / 2018$ \\
\hline
\end{tabular}

** Sample covered the duration of the * samples. 